\title{
Infliximab enhances the therapeutic effects of 5 -fluorouracil resulting in tumor regression in colon cancer
}

This article was published in the following Dove Press journal:

OncoTargets and Therapy

3 October 2016

Number of times this article has been viewed

\author{
Fen Liu ${ }^{1,2}$ \\ Feiyan $\mathrm{Ai}^{1,2}$ \\ Li Tian' \\ Shaojun Liu' \\ Lian Zhao ${ }^{1,2}$ \\ Xiaoyan Wang ${ }^{1,2}$ \\ 'Department of Gastroenterology, \\ The Third Xiangya Hospital of \\ Central South University, ${ }^{2}$ Hunan \\ Key Laboratory of Nonresolving \\ Inflammation and Cancer, Changsha, \\ Hunan, People's Republic of China
}

Correspondence: Xiaoyan Wang Department of Gastroenterology, The Third Xiangya Hospital of Central South University, Changsha 4I0000, Hunan, People's Republic of China Tel +86 73I 88638888 Email xiaoyw06@163.com

\begin{abstract}
Colon cancer (CC) is among the most common malignant diseases with a dismal survival. Tumor necrosis factor-alpha (TNF- $\alpha$ ) has been identified as a therapeutic target in various cancers, and anti-TNF- $\alpha$ treatment has shown promising effects in different cancer models. However, if TNF- $\alpha$ can be targeted in CC, the therapeutic values of anti-TNF- $\alpha$ treatment in CC remain unknown. Our study indicated that TNF- $\alpha$ is highly expressed in CC cell lines and patient tumor samples. High expression of TNF- $\alpha$ is an independent adverse prognosticator of CC. Targeting the TNF- $\alpha$ by its antibody infliximab induced antibody-dependent cellular cytotoxicity and complement-dependent cytotoxicity and enhanced apoptosis leading to cell death. The combination of infliximab with 5-fluorouracil showed better responses in vitro and in vivo than 5-fluorouracil alone. In conclusion, this study identified TNF- $\alpha$ as a target of $\mathrm{CC}$ and anti-TNF- $\alpha$ treatment synergized with chemotherapy leading to a better outcome in preclinical models.
\end{abstract}

Keywords: colon cancer, tumor necrosis factor-alpha, chemotherapy, prognosis, tumor regression

\section{Introduction}

Colon cancer (CC) has long been one of the major cancers and remains the common cause of malignant disease mortality worldwide. ${ }^{1,2}$ In Australia/New Zealand, Europe, and Northern America, CC is one of the most prevalent cancer types and the leading cause of the cancer-related deaths. ${ }^{1}$ In early stage CC patients, 5-year survival rate after surgical treatment has reached $>90 \% .{ }^{1}$ However, the majority of $\mathrm{CC}$ patients diagnosed with regional invasion and metastatic disease have significantly decreased overall 5-year survival rate, $\sim 70 \%$ and $10 \%$, respectively. ${ }^{1}$ 5-Fluorouracil (5-FU)-based chemotherapy is widely used in advanced CC; however, chemoresistance occurs in most cases and leads to patients' death. ${ }^{3}$ As a result, novel therapies that synergize with the current drugs to enhance chemotherapeutic effects in the treatment of CC are greatly needed.

Tumor necrosis factor- $\alpha$ (TNF- $\alpha$ ) was discovered and named in 1975 due to its capacity for killing mouse L929 fibrosarcoma cells. ${ }^{4}$ TNF- $\alpha$ is primarily produced as a 233-amino-acid transmembrane protein arranged in stable homotrimers. ${ }^{5}$ The soluble form of TNF- $\alpha$ (sTNF- $\alpha$ ) is released via proteolytic cleavage from its membraneintegrated form (mTNF- $\alpha$ ). Although the secreted and the membrane-bound forms have different functions, they are biologically active. ${ }^{6}$ TNF- $\alpha$ binds to two receptors, TNF receptor 1 (TNFR1) and TNF receptor 2 (TNFR2). Different from TNFR2, which 
only expresses in immune cells and responds to the membrane form of TNF- $\alpha$, TNFR1 is widely expressed and can be fully activated by both sTNF- $\alpha$ and mTNF- $\alpha .{ }^{6}$ Upon TNF- $\alpha$ and TNFR1 interaction, three downstream pathways can be initiated: nuclear factor (NF)- $\mathrm{KB}$ pathway, mitogen-activated protein kinase pathway, and cell death signaling. Owing to the complex nature of cell signaling, various biological functions that are vital in cellular functions are activated, including antiapoptosis, proinflammation, and cell proliferation.

Although TNF- $\alpha$ was initially discovered as a killer of tumor cells, the following studies demonstrated far more complicated functions of TNF- $\alpha$ in cancers. It was known that many malignant cells constitutively produce TNF- $\alpha$ in vivo. ${ }^{7}$ Evidence from animal models showed that this malignant cell-derived TNF- $\alpha$ enhances the tumorigenesis and development of syngeneic, xenogeneic, and carcinogen-induced tumors of the skin, ovary, and pleural cavity. ${ }^{8-10}$ Further investigations using TNF- $\alpha$ antagonist revealed target value of TNF- $\alpha$ in cancer. Anti-TNF- $\alpha$ antibodies infliximab and etanercept achieved promising antitumor effects in preclinical models and clinical trials of renal cancer, breast cancer, and pancreatic cancer. ${ }^{11-13}$ However, the target value and functions of TNF- $\alpha$ in $\mathrm{CC}$, especially in $\mathrm{CC}$ treatment, remain unclear. Here, we sought to investigate these effects.

\section{Patients and methods}

\section{Cell culture}

Human CC cell lines HCT116 and HT29 were obtained from the Cell Bank of Type Culture Collection of Chinese Academy of Sciences (Shanghai, People's Republic of China). The cell lines were cultured with Roswell Park Memorial Institute 1640 Medium (Thermo Fisher Scientific, Waltham, MA, USA) containing 5\% fetal bovine serum, $100 \mathrm{mg} / \mathrm{mL}$ streptomycin, and $100 \mathrm{U} / \mathrm{mL}$ penicillin in a humidified $5 \% \mathrm{CO}_{2}$ incubator at $37^{\circ} \mathrm{C}$. Subculture was performed at $70 \%$ confluence of each cell line.

\section{Analysis of patient samples}

Formalin-fixed, paraffin-embedded (FFPE) tumor tissues were collected from $90 \mathrm{CC}$ patients diagnosed from February 2009 to August 2014 at the The Third Xiangya Hospital of Central South University. Six fresh tumor and adjacent tissues were obtained from three CC patients as well. All tissues were collected before chemotherapy or radiotherapy. The FFPE tissues were used to conduct immunohistochemistry (IHC) staining. The fresh tissues were immediately dissociated into single cells suspension after the resection, and the cell pallets were lysed by radioimmunoprecipitation assay buffer with protease inhibitor for enzyme-linked immunosorbent assay (ELISA). Written informed consent was obtained from each patient, and approval from the local medical ethics and human clinical trial committee of the The Third Xiangya Hospital of Central South University was issued. Grades of differentiation were determined according to the World Health Organization's criteria of CC. ${ }^{14}$ Tumor-node-metastasis classification was determined following the AJCC Cancer Staging Manual, seventh edition. ${ }^{15}$ Clinicopathological features of these $\mathrm{CC}$ patients are listed in Table 1. Ninety $\mathrm{CC}$ patients were followed up from the date of surgery to January 2015. Overall survival was defined as the interval from the date of surgery to death. The patients who died of other diseases or due to unexpected events were excluded from the final survival analysis.

\section{Cell viability assay}

Cell viability assay was conducted using Cell Counting Kit-8 (CCK-8; Sigma-Aldrich Co., St Louis, MO, USA) following the manufacturer's instructions. Cells $\left(5 \times 10^{3} /\right.$ well $)$ were

Table I Relationship between TNF- $\alpha$ expression and clinicopathological features of CC

\begin{tabular}{|c|c|c|c|}
\hline \multirow[t]{2}{*}{ Parameters } & \multicolumn{3}{|c|}{ TNF- $\alpha$ expression } \\
\hline & Low, n (\%) & High, n (\%) & $P$-value \\
\hline \multicolumn{4}{|l|}{ Age (years) } \\
\hline$<61$ & $26(54.2)$ & $22(48.5)$ & 0.955 \\
\hline$\geq 61$ & $23(54.8)$ & $19(45.2)$ & \\
\hline \multicolumn{4}{|l|}{ Sex } \\
\hline Male & $30(48.4)$ & $32(51.6)$ & 0.086 \\
\hline Female & $19(67.9)$ & $9(32.1)$ & \\
\hline \multicolumn{4}{|l|}{ T stage } \\
\hline $\mathrm{TI}+\mathrm{T} 2$ & $8(53.3)$ & $7(46.7)$ & 0.925 \\
\hline $\mathrm{T} 3+\mathrm{T} 4$ & $4 \mid(54.7)$ & $34(45.3)$ & \\
\hline \multicolumn{4}{|l|}{ Lymph node } \\
\hline N0-N2 & $35(56.5)$ & $27(43.5)$ & 0.569 \\
\hline N3-N4 & $14(50)$ & $14(50)$ & \\
\hline \multicolumn{4}{|l|}{ Metastasis } \\
\hline Negative & $48(54.5)$ & $40(45.5)$ & 0.898 \\
\hline Positive & I (50) & I (50) & \\
\hline \multicolumn{4}{|l|}{ TNM stage } \\
\hline$I+I I$ & $18(52.9)$ & $16(47.1)$ & 0.823 \\
\hline III + IV & $31(55.4)$ & $25(44.6)$ & \\
\hline \multicolumn{4}{|l|}{ Pathological grade } \\
\hline Low and medium & $18(5 \mathrm{l} .4)$ & $17(48.6)$ & 0.647 \\
\hline High & $31(56.4)$ & $24(43.6)$ & \\
\hline \multicolumn{4}{|l|}{ Pathological type } \\
\hline Ductal adenocarcinoma & $31(58.5)$ & $22(4 \mid .5)$ & 0.356 \\
\hline Others & $18(48.6)$ & $19(51.4)$ & \\
\hline \multicolumn{4}{|l|}{ Survival status } \\
\hline Alive & $27(69.2)$ & $12(30.8)$ & 0.014 \\
\hline Dead & $22(43.1)$ & $29(56.9)$ & \\
\hline
\end{tabular}

Note: Data in bold indicates statistical significance $(P<0.05)$.

Abbreviations: TNF- $\alpha$, tumor necrosis factor-alpha; CC, colon cancer; TNM, tumornode-metastasis. 
seeded in 96-well plates in $100 \mu \mathrm{L}$ culture medium containing gradient concentrations of infliximab and/or fluorouracil (5-FU) and cultured for 48 hours. Then $10 \mu \mathrm{L}$ of CCK-8 solution was added to each well for incubation for 30 minutes at $37^{\circ} \mathrm{C}$. After incubation, absorbance $(450 \mathrm{~nm})$ was measured by MRX II microplate reader (Dynex Technologies, Chantilly, VA, USA). The cell viability was calculated based on the formula as follows:

Treatment (optical density [OD] $450 \mathrm{~nm}$ ) - Blank (OD $450 \mathrm{~nm}$ ) Control (OD $450 \mathrm{~nm}$ ) - Blank (OD $450 \mathrm{~nm})$

\section{Fluorescence-activated cell sorter analysis}

Fluorescence-activated cell sorter (FACS) analysis was used to detect the expression of TNF- $\alpha$ (Abcam, Cambridge, MA, USA) and cleaved caspase-3 (Abcam) in designated conditions. Suspended cells collected from tissue culture were stained with TNF- $\alpha$ antibody for 20 minutes at room temperature. Cleaved caspase- 3 was used to evaluate cell apoptosis. The cells treated with different drugs were collected and permeabilized for cleaved caspase- 3 staining for 20 minutes at room temperature. Then, the cells were washed with phosphate-buffered saline (PBS) and incubated with fluorescence-labeled secondary antibodies for 15 minutes at room temperature. After washing with PBS three times, the stained cells were analyzed by an FACSCanto II machine (BD, Franklin Lakes, NJ, USA). FlowJo software was used for data visualization.

\section{Antibody-dependent cellular cytotoxicity and complement-dependent cytotoxicity assay}

For antibody-dependent cellular cytotoxicity (ADCC) assay, the target cells were prepared by seeding human $\mathrm{CC}$ tumor cell lines HCT116 and HT29 into 96-well plates (2,000 cells per well). Effector cells were prepared by isolating macrophages from peritoneal cavity flushing fluid of BALB/c mice. Before mixing with effector cells, the target cells were preincubated with infliximab for 1 hour at $37^{\circ} \mathrm{C}$. Then, the mixture of target cells and effector cells with a ratio of 1:20 were incubated for 48 hours at $37^{\circ} \mathrm{C}$. In the complementdependent cytotoxicity (CDC) assay, the target cells with a density of 5,000/well in 96-well plates were incubated with $5 \%$ fresh guinea pig serum containing active complements and infliximab for 6 hours at $37^{\circ} \mathrm{C}$. Finally, CCK-8 assay (Sigma-Aldrich Co.) as mentioned earlier was used to evaluate the cell viability for both ADCC and CDC assays.
The method for calculating the cytotoxicity was the same as published previously. ${ }^{12}$

\section{Xenograft mouse model}

In order to analyze the in vivo activity of 5-FU and infliximab, the xenograft mouse model was established using 6-week-old female BALB/c nude mice (21-23 g; Shanghai SLAC Laboratory Animal Center of Chinese Academy of Sciences, Shanghai, People's Republic of China). All nude mice were raised under the specific pathogen-free environment with free access to autoclaved water, standard food, and 12-hour light every day. Each nude mouse was injected $3 \times 10^{6}$ HCT 116 cells at the flank of hind legs. Ten mice were assigned to each group. Seven days after the injection, all mice were randomly divided into three groups for different treatments: 1) saline; 2) 5-FU (20 mg/kg/wk); and 3) 5-FU $(20 \mathrm{mg} / \mathrm{kg} / \mathrm{wk})+$ infliximab $(10 \mathrm{mg} / \mathrm{kg} / \mathrm{wk})$. Tumor growth was monitored every 5 days. Tumor volume was calculated based on the widely accepted formula:

$$
\text { Tumor volume }=\text { Length } \times \mathrm{Width}^{2} \times \pi / 6
$$

Body weight and survival of all mice were also documented. All animal experiments were approved by the Animal Care and Use Committee of the The Third Xiangya Hospital of Central South University. All animal-handling procedures were performed according to the Guide for the Care and Use of Laboratory Animals of the National Institutes of Health and followed the guidelines of the Animal Welfare Act.

\section{Immunohistochemistry}

Standard IHC protocol was followed to stain the FFPE human CC tumor tissues using TNF- $\alpha$ antibody (Abcam) and xenograft mouse model CC tissue using cleaved poly(ADP-ribose) polymerase (PARP) antibody (Abcam). In brief, $4 \mu \mathrm{m}$ of FFPE tissue sections were deparaffinized with xylene and incubated with 3\% $\mathrm{H}_{2} \mathrm{O}_{2}$ in methanol for 20 minutes in the dark to block the endogenous peroxidase activity. Then, tissue sections were rehydrated with gradient ethanol and subjected to antigen retrieval by streaming with Reveal Decloaker (Biocare Medical, Concord, CA, USA) for 40 minutes. The slides were washed using PBS with Tween 20 , followed by blocking with $5 \%$ bovine serum albumin buffer incubation at room temperature for 10 minutes. Then, diluted primary TNF- $\alpha$ antibody (1:100) and cleaved PARP antibody (1:100) were added for incubation overnight at $4^{\circ} \mathrm{C}$. After washing with PBS with Tween 20 three times, horseradish peroxidase-conjugated secondary antibody was added and incubated for 1 hour at room temperature. 
Then, DAB (3,3'-Diaminobenzidine) was used, and slides were immediately washed under tap water after the color development. The primary antibody was omitted for the negative controls. The slides were then mounted and observed under a light microscope. The scoring of TNF- $\alpha$ was based on the positive area proportion identified in ImageJ. We assigned 1 to $1 \%-33 \%$ positive, 2 to $34 \%-67 \%$ positive, and 3 to $>67 \%$ positive.

\section{Enzyme-linked immunosorbent assay}

To quantify TNF- $\alpha$ level in the CC tissue in an unbiased way, we conducted ELISA. CC tumor tissues and tumor adjacent tissues were dissociated into single-cell suspension, and cell pallets were lysed by radioimmunoprecipitation assay buffer with the protease inhibitor. ELISA procedures followed the recommendation of the manufacturer (Abcam).

\section{Statistical analysis}

Statistical analyses were performed using SPSS 17.0 software (SPSS Inc., Chicago, IL, USA) and GraphPad (GraphPad Software, Inc., La Jolla, CA, USA). All quantification data were expressed as mean $\pm \mathrm{SD}$, except those with specific statement. One-way analysis of variance and two-sample $t$-test were used to analyze the difference between individual groups. Bonferroni's pairwise comparisons were conducted following one-way analysis of variance. For categorical parameters, chi-square analysis was applied. Receiver operating characteristic curve was used to determine the cutoff point of low TNF- $\alpha$ expression and high TNF- $\alpha$ expression. The relationship between TNF- $\alpha$ level and $\mathrm{CC}$ patient survival was plotted by Kaplan-Meier survival analysis. Log-rank test was conducted to quantify the difference of survival between $\mathrm{CC}$ patients with high TNF- $\alpha$ expression and low TNF- $\alpha$ expression. Multivariate Cox regression was used to find the parameters that are independent predictors of survival of CC patients based on the hazard ratio and $95 \%$ confidence interval. Detailed information about survival analysis was the same as the previous report. ${ }^{16}$ For all statistic tests, two-tailed $P$-values $<0.05$ were considered statistically significant.

\section{Results}

\section{TNF- $\alpha$ is highly expressed in CC}

We tested the TNF- $\alpha$ expression in human $\mathrm{CC}$ tumor cell lines HCT116 and HT29 using FACS and in tumor tissues and tumor adjacent tissues using ELISA (Figure 1). As shown in Figure $1 \mathrm{~A}$ and $\mathrm{B}$, there was apparent TNF- $\alpha$ expression in both HCT116 and HT29 cell lines, which indicated that TNF- $\alpha$ was highly expressed in these two cell lines. The quantification analysis of median fluorescence intensity confirmed this finding (Figure 1C and D). Consistently, the TNF- $\alpha$ expression in the $\mathrm{CC}$ tumor tissue is significantly higher than that in tumor adjacent tissues (Figure 1E). Therefore, we showed that TNF- $\alpha$ expression was increased in the $\mathrm{CC}$ tissues and it could be a potential target for $\mathrm{CC}$ treatment.

\section{High expression of TNF- $\alpha$ is an independent prognosticator of CC}

In order to further explore the target value of TNF- $\alpha$ in $\mathrm{CC}$, the relationship between TNF- $\alpha$ expression and $\mathrm{CC}$ patient characteristics was determined and survival analysis was conducted. Figure 2A shows the representative IHC staining of CC tumor tissues. The clinicopathological features of these patients are summarized in Table 1. Chi-square analysis indicated that the survival status of these $\mathrm{CC}$ patients was significantly associated with the TNF- $\alpha$ expression levels. Patients who died of CC tended to have higher expression of TNF- $\alpha$, while patients who were alive tended to have lower TNF- $\alpha$ level (Table 1). However, no significant relationship between TNF- $\alpha$ expression and other parameters was discovered. For survival analysis, we used receiver operating characteristic analysis to determine the cutoff point of high or low TNF- $\alpha$ expression (Figure 2B). We plotted the survival status and TNF- $\alpha$ expression by the Kaplan-Meier method (Figure 2C). For the purpose of identifying if TNF- $\alpha$ is an independent prognosticator, multivariate analysis based on the Cox model was conducted. We found that lymph node status, grade of differentiation, and TNF- $\alpha$ independently predicted survival of CC patients in our cohort (Table 2).

\section{ADCC and CDC effects induced by infliximab result in death of $C C$ cells in vitro}

Considering we had already observed its high expression in $\mathrm{CC}$ tumor tissues and cell lines and its prognostic value, we explored TNF- $\alpha$ 's role in killing CC cells. Infliximab is an anti-TNF- $\alpha$ monoclonal antibody that is widely used to inhibit TNF- $\alpha$ functions. We treated human CC tumor cell lines HCT116 and HT29 with increasing concentrations of infliximab, but no direct cytotoxicity was observed in either of these two cell lines, showing little reduction of cell viability (Figure 3A and B). However, in the presence of effector macrophages or active complements, the cell viability of both HCT116 and HT29 cell lines was significantly decreased by the increasing concentrations of infliximab (Figure $3 \mathrm{~A}$ and B). Thus, we believe that anti-TNF- $\alpha$ treatment could be a potential therapy for $\mathrm{CC}$ via inducing $\mathrm{ADCC}$ and $\mathrm{CDC}$ effects. 
A

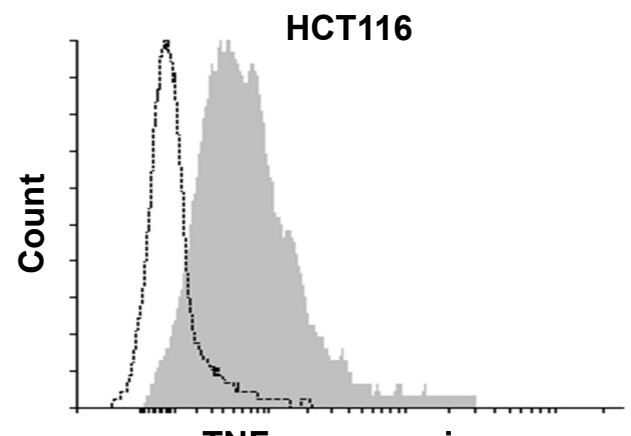

TNF- $\alpha$ expression

C



HCT116

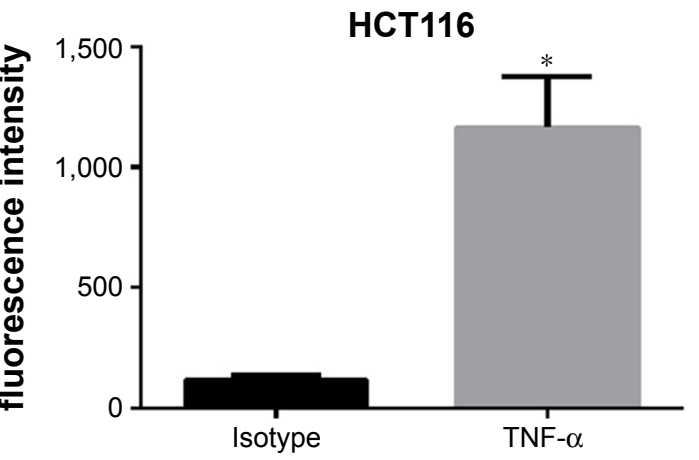

$\mathbf{E}$

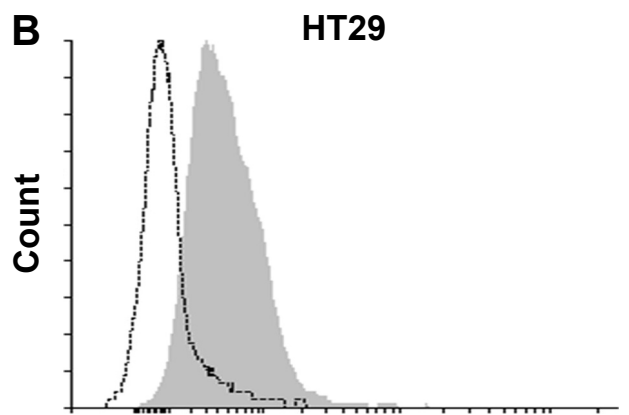

TNF- $\alpha$ expression

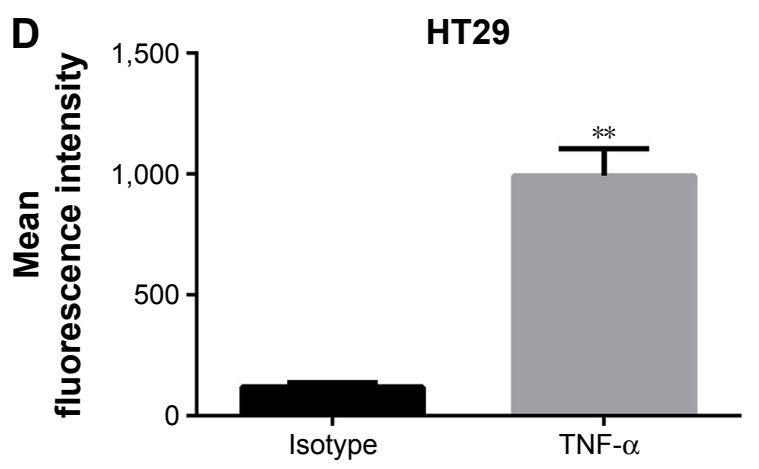

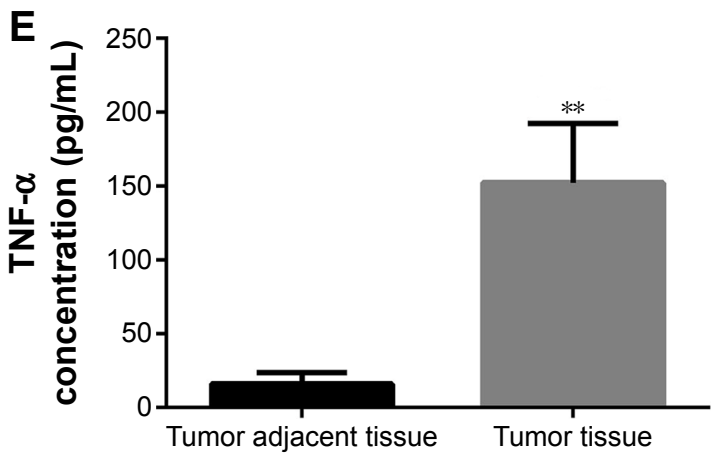

Figure I TNF- $\alpha$ is overexpressed in CC.

Notes: TNF- $\alpha$ expression in CC cell lines HCTII6 and HT29 was measured using FACS analysis (gray peak shows the TNF- $\alpha$ expression in CC cell lines and white peak shows the value of isotype). (A and $\mathbf{C}$ ) TNF- $\alpha$ was highly expressed in the CC cell line HCTII6. (B and D) TNF- $\alpha$ was highly expressed in the CC cell line HT29. (E) TNF- $\alpha$ expression in CC tumor tissue and tumor-adjacent tissues was measured using ELISA. Comparing with tumor adjacent tissues, CC tumor tissues had much higher TNF- $\alpha$ concentration. ${ }^{*} \mathrm{P}<0.05$, $* * \mathrm{P}<0.01$.

Abbreviations: TNF- $\alpha$, tumor necrosis factor-alpha; CC, colon cancer; FACS, fluorescence-activated cell sorter; ELISA, enzyme-linked immunosorbent assay.

\section{Infliximab enhances 5-FU effects via inducing apoptosis in CC cells}

Having shown that infliximab decreased cell viability of CC cell lines, we further tested whether there was a synergic effect of infliximab with 5-FU in killing CC cells. In the presence of complement, administration of infliximab further decreased cell viability of 5-FU-treated HCT116 and HT29 cell lines (Figure 4A and B). As TNF- $\alpha$ downstream pathways are involved in antiapoptosis in cancers, we investigated if anti-TNF- $\alpha$ treatment can enhance the role of 5-FU in inducing apoptosis in CC. HCT116 and HT29 cell lines were treated with $1 \mathrm{mg} / \mathrm{mL}$ of $5-\mathrm{FU}$ plus $16 \mu \mathrm{g} / \mathrm{mL}$ of infliximab in the presence of complement. As shown in Figure $4 \mathrm{C}$ and D, an increased level of cleaved caspase-3 was observed after 5-FU treatment. Addition of infliximab further enhanced the level of cleaved caspase-3. Therefore, these data suggested that the anti-TNF- $\alpha$ treatment promoted the therapeutic effects of 5-FU in CC by inducing cell apoptosis.

\section{Infliximab enhances 5-FU therapeutic effects in CC xenograft mouse model}

In line with the in vitro study, infliximab treatment also increased the 5-FU-induced apoptosis in the CC xenograft mouse model. We observed more cleaved PARP positive cells in the combination treatment group than in the 5-FU single treatment group (Figure 5). Monitoring of tumor volume 
A

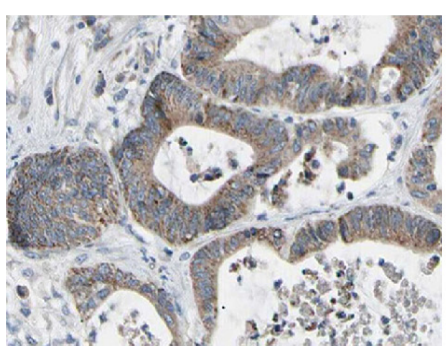

B

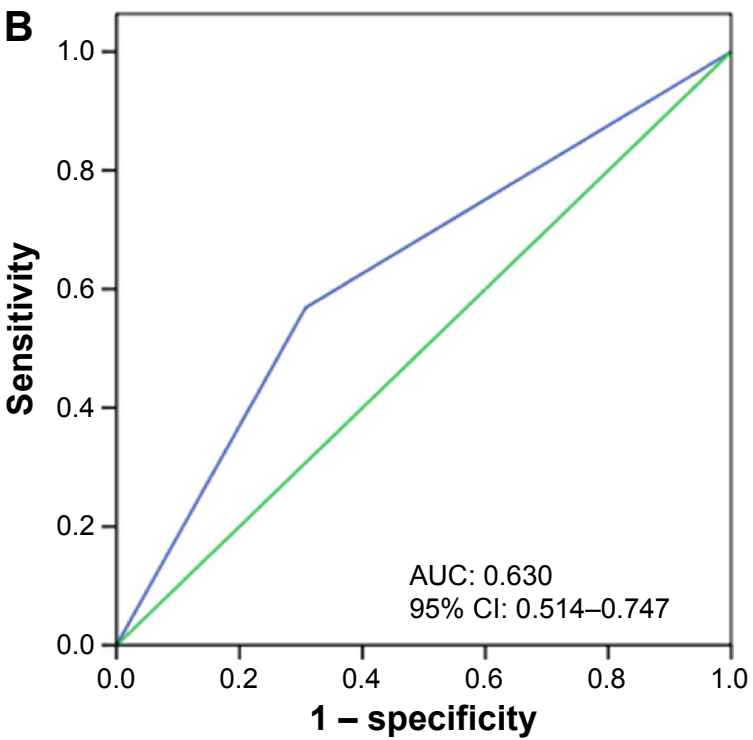

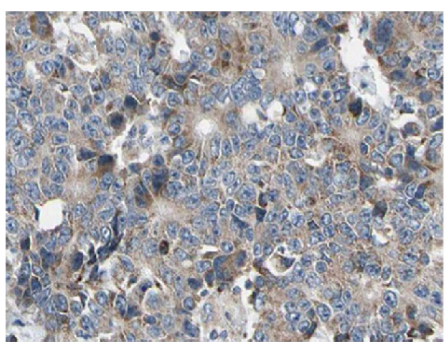
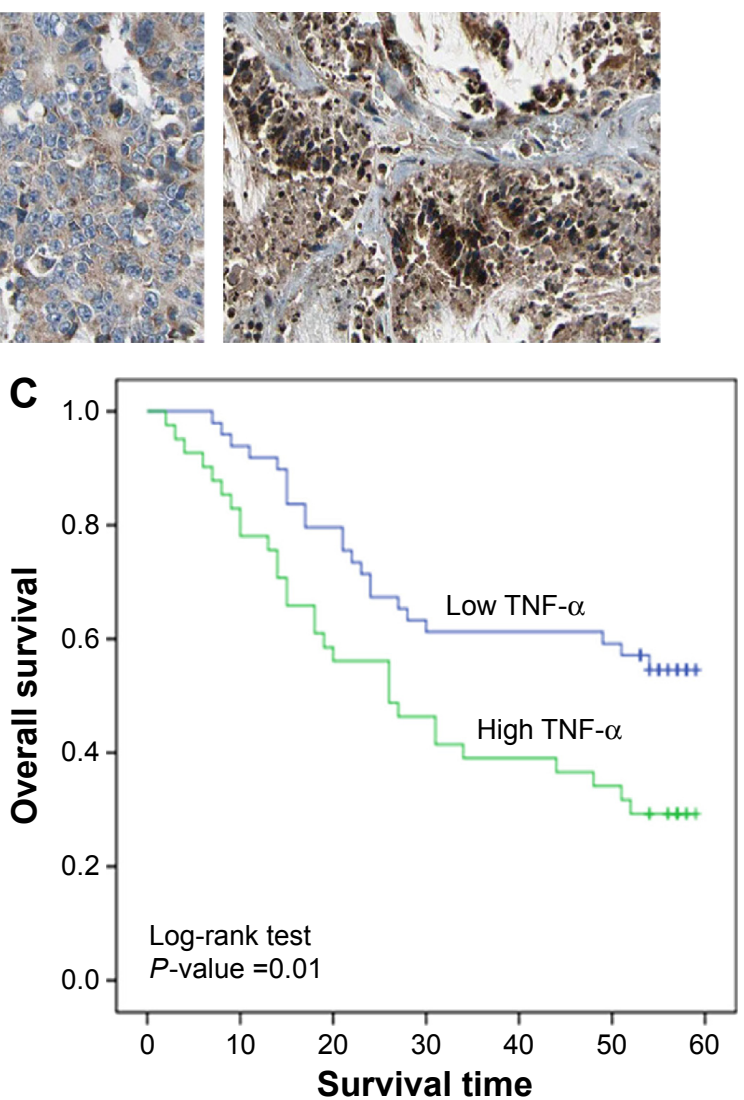

Figure 2 High expression of TNF- $\alpha$ predicts poor survival in $C C$ patients.

Notes: (A) TNF- $\alpha$ expression in the CC patient tissue was tested by IHC. Here we show the representative pictures of low, medium, and high expressions of TNF- $\alpha$ in CC (from left to right). The brown color indicates TNF- $\alpha$ expression. (B) ROC analysis determined medium expression as dichotomy cutoff point for survival analysis with $0.630 \mathrm{AUC}(95 \% \mathrm{Cl}=0.5 \mathrm{I} 4-0.747)$. (C) Survival analysis by the Kaplan-Meier method and log-rank test showed that high expression of TNF- $\alpha$ correlated with poor survival of $C C$ patients $(P=0.01)$. The blue curve shows the survival curve of $C C$ patients with low TNF- $\alpha$ expression, and the green curve shows the survival curve of $C C$ patients with high TNF- $\alpha$ expression.

Abbreviations: TNF- $\alpha$, tumor necrosis factor-alpha; CC, colon cancer; IHC, immunohistochemistry; ROC, receiver operating characteristic; AUC, area under the curve; $\mathrm{Cl}$, confidence interval.

demonstrated tumor growth delay in the combination treatment group compared with the 5-FU single treatment group (Figure 6A). As the best standard of treatment response evaluation, survival time was also recorded. As Figure 6B indicates,

Table 2 Multivariate Cox proportional hazard models on OS of $\mathrm{CC}$ patients

\begin{tabular}{|c|c|c|}
\hline Factors & $P$-value & HR $(95 \% \mathrm{Cl})$ \\
\hline Sex (male vs female) & 0.903 & $0.926(0.5 \mid 8-1.787)$ \\
\hline Age $(\geq 6$ I years vs $<6$ I years) & 0.098 & 1.711 (0.906-3.230) \\
\hline TNM stage (III-IV vs I-II) & 0.668 & $1.205(0.515-2.819)$ \\
\hline T stage (T3-T4 vs TI-T2) & 0.333 & $1.81 \mathrm{I}(0.545-6.015)$ \\
\hline Lymph node (N3-N4 vs N0-I & 0.049 & $1.968(1.004-3.859)$ \\
\hline Metastasis (yes vs no) & 0.112 & $3.634(0.724-17.81)$ \\
\hline $\begin{array}{l}\text { Pathological type (ductal } \\
\text { adenocarcinoma vs others) }\end{array}$ & 0.852 & 0.940 (0.49I-I.799) \\
\hline $\begin{array}{l}\text { Grade of AC (poorly vs well and } \\
\text { moderately) }\end{array}$ & 0.011 & $2.546(1.243-5.213)$ \\
\hline TNF- $\alpha$ expression (high vs low) & 0.006 & $2.314(1.270-4.213)$ \\
\hline
\end{tabular}

Note: Data in bold indicates statistical significance $(P<0.05)$.

Abbreviations: OS, overall survival; $\mathrm{CC}$, colon cancer; $\mathrm{HR}$, hazard ratio; $\mathrm{Cl}$, confidence interval; TNM, tumor-node-metastasis; TNF- $\alpha$, tumor necrosis factoralpha; AC, advanced cancer. the combination treatment group had the longest survival time (5-FU vs infliximab + 5-FU: log-rank test $P$-value $=0.0048$ ) Taken together, we believe that infliximab can promote the therapeutic effects of 5-FU in vitro as well as in vivo.

\section{Discussion}

Use of TNF- $\alpha$ antibody infliximab has been reported in various cancer models, including skin cancer, pancreatic cancer, breast cancer, and leukemia with significant effects observed. ${ }^{8,12,13,17} \mathrm{CC}$ is listed as the most prevalent malignant disease regarding its incidence and mortality. Although multiple biomarkers have been identified and comprehensive treatments have been applied, the overall prognosis of advanced CC remains dismal. ${ }^{1,18-20}$ In CC, the effects of anti-TNF- $\alpha$ treatment using infliximab have not been investigated. Here, as far as our knowledge, we are first to report the targeting significance of TNF- $\alpha$ and the synergistic roles of anti-TNF- $\alpha$ treatment with chemotherapy in CC.

Mounting studies have shown that a low level of TNF- $\alpha$ is ubiquitously expressed in many tissues. However, 

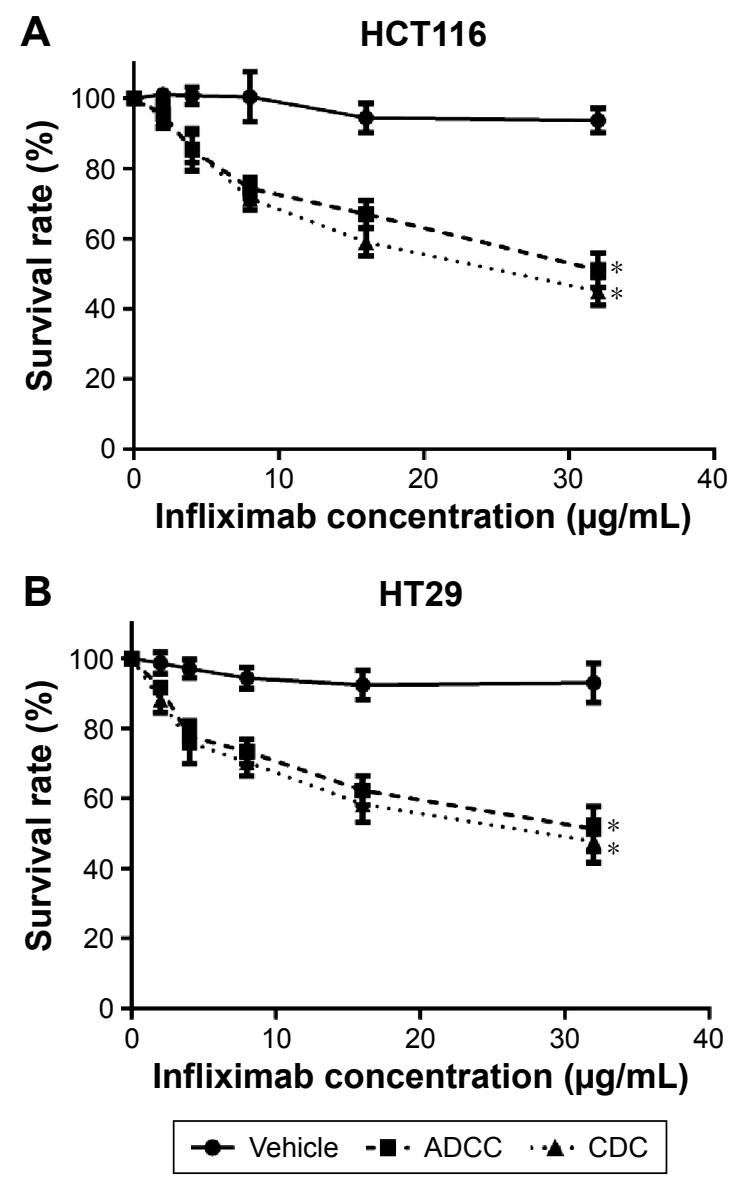

Figure 3 Infliximab inhibits $C C$ cells' viability via $A D C C$ and $C D C$ effects. Notes: $A D C C$ and $C D C$ effects were reflected by the reduction in the cell viability of CC cell lines HCTII6 and HT29 cultured with effector cells (macrophage) or active complement with infliximab treatment. (A and B) In the control group, with the increase in infliximab concentration, neither HCTII 6 cell line nor HT29 cell line had an apparent reduction in cell viability. This suggested that there was no direct cytotoxicity of infliximab on CC cell lines. However, with the presence of effector cells and complement, infliximab decreased CC cells' viability significantly with the increasing dose. $* P<0.05$.

Abbreviations: $C C$, colon cancer; $A D C C$, antibody-dependent cellular cytotoxicity; $\mathrm{CDC}$, complement-dependent cytotoxicity.

its expression could be changed under abnormal contexts, such as tumors. In line with a previous study of other cancers that indicated that TNF- $\alpha$ was highly expressed in tumor cells and tissues, our data revealed that $\mathrm{CC}$ cells and tumor tissues also have a high amount of TNF- $\alpha$. In two widely used CC cell lines, HCT116 and HT29, a high level of TNF- $\alpha$ was detected. ${ }^{12}$ More significantly, a much larger amount of TNF- $\alpha$ was detected by the ELISA method in the fresh human $\mathrm{CC}$ tissues than in the tumor adjacent tissues. These data suggested potential target value of TNF- $\alpha$ in CC. To further evaluate this target value, we analyzed the prognostic significance of TNF- $\alpha$ in $\mathrm{CC}$ patients. Our analysis found that TNF- $\alpha$ was widely expressed in the tissues of CC patients and high expression of TNF- $\alpha$ was an independent prognosticator of CC. Taken together, our results indicate in concordance with other tumors, such as breast cancer, pancreatic cancer, and leukemia. ${ }^{12,13,17} \mathrm{TNF}-\alpha$ in $\mathrm{CC}$ also has strong prognostic value and should be targeted.

The cytotoxic impacts of antibody-based treatments in tumors can be either direct cytotoxicity, ADCC effect, and/or CDC effect. ${ }^{21}$ It was reported that anti-TNF- $\alpha$ antibodies showed obvious ADCC and CDC effects rather than direct cytotoxicity in cancers. ${ }^{12,22}$ In line with these previous studies, we also found that no significant direct cytotoxic effect of antiTNF- $\alpha$ antibody treatment was seen in CC cell lines. On the contrary, ADCC and CDC effects induced by infliximab considerably decreased cell viability in CC cell lines. TNF- $\alpha$ and TNFR1 binding can induce a range of downstream pathways, including NF- $\kappa \mathrm{B}$ pathway. NF- $\kappa \mathrm{B}$ activation importantly induces negative regulators of apoptosis such as Bcl-2 and FLIPL. ${ }^{23,24}$ Expression of TNF- $\alpha$ in tumors consistently activates NF- $\kappa \mathrm{B}$ pathway and thus promotes apoptosis resistance. To clarify the mechanisms of infliximab-induced cell death in $\mathrm{CC}$, we measured apoptosis level in vitro and in vivo. Our findings supported that by blocking the TNF- $\alpha$ and TNFR1 interaction, more apoptotic cells were observed in the presence of chemotherapy drug 5-FU. Therefore, other than ADCC and $\mathrm{CDC}$ effects, the infliximab treatment suppresses tumor development by enhancing apoptosis in cancer cells.

Based on the findings that TNF- $\alpha$ can be targeted in $\mathrm{CC}$ and anti-TNF- $\alpha$ treatment can induce ADCC and CDC effects and enhance apoptosis, we further expected that infliximab treatment could synergize with chemotherapy in $\mathrm{CC}$ in vitro and in vivo. Our in vitro experiments based on the cell viability assay demonstrated that infliximab and 5-FU combination treatment significantly decreased cell viability compared to single treatment with 5-FU. In the HCT116 cell line xenograft mouse model, the combination therapy also dramatically inhibited tumor growth and prolonged animal survival time with a small 5-FU treatment dose that can be fully tolerated by animals. Although we saw infliximab-enhanced effects of 5 -FU in high dose in vitro, we did not see similar effects in the HT29 cell line xenograft (data not shown). This may be because HT29 cell line is not sensitive to small doses of 5-FU in vivo as is the HCT116 cell line. ${ }^{25}$ Taken together, in agreement with our hypothesis, anti-TNF- $\alpha$ treatment could enhance the therapeutic effects of chemotherapy, resulting in CC tumor regression and better survival in preclinical models.

Chemoresistance remains the major challenge of $\mathrm{CC}$ treatment in patients with advanced disease. In this study, we identified that TNF- $\alpha$ is an independent prognosticator and can be targeted in $\mathrm{CC}$. Treatment of $\mathrm{CC}$ with infliximab enhanced the therapeutic effects of chemotherapy; therefore, more clinically relevant investigations combining chemotherapy and anti-TNF- $\alpha$ treatment are warranted. 


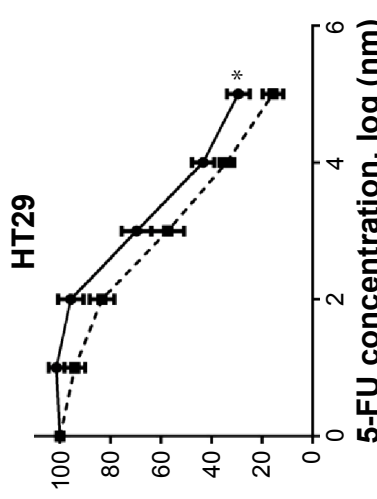

(\%) әүеג ןем!n.uns

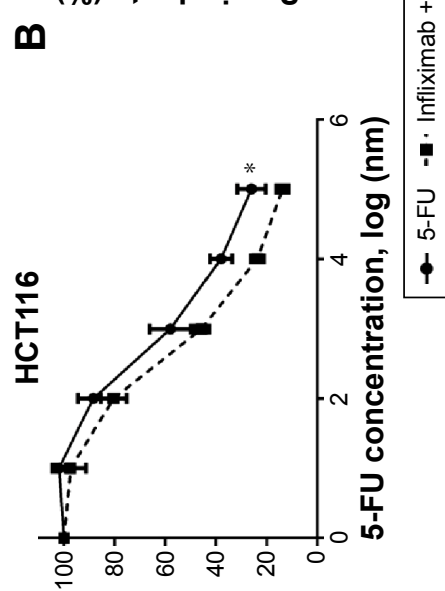

(\%) әред ןем!n.uns

$\varangle$

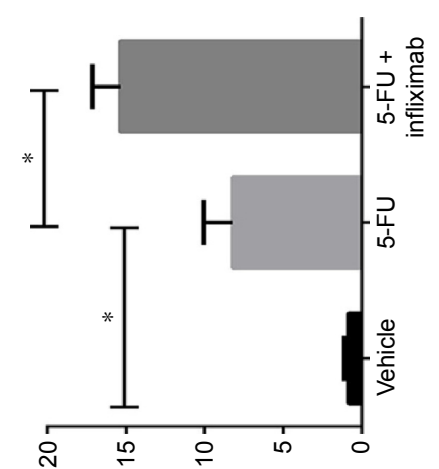

(\%) әрел

ио!ןел!ฺюе ع-әsedseว
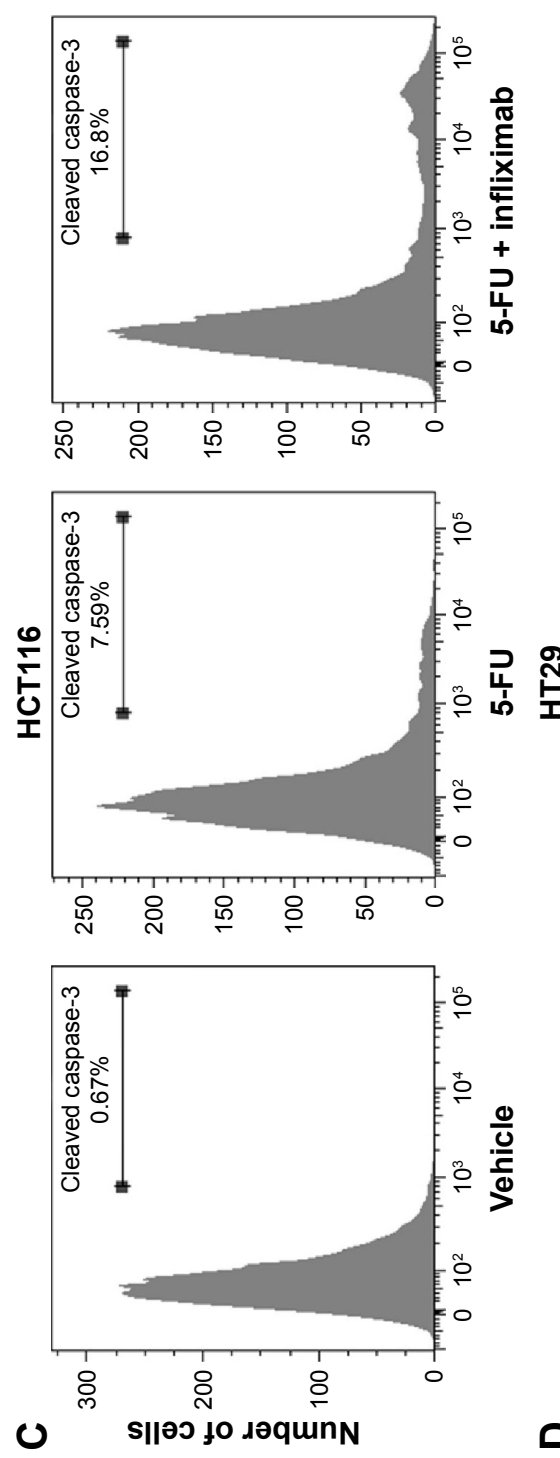

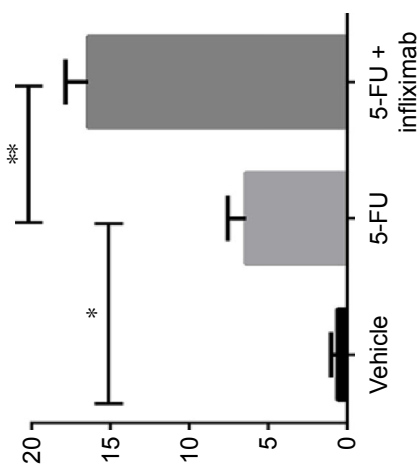

(\%) әұеג

uo!ןen!ןoe ع-әsedseว

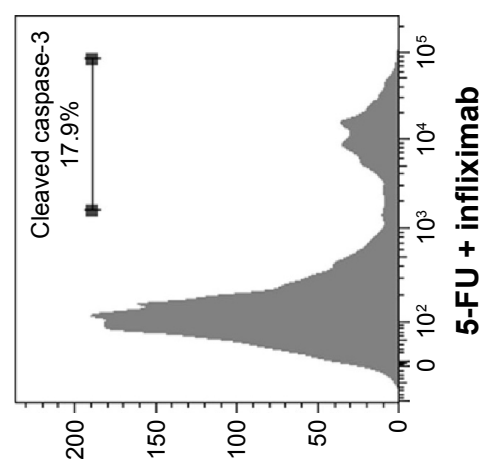

过
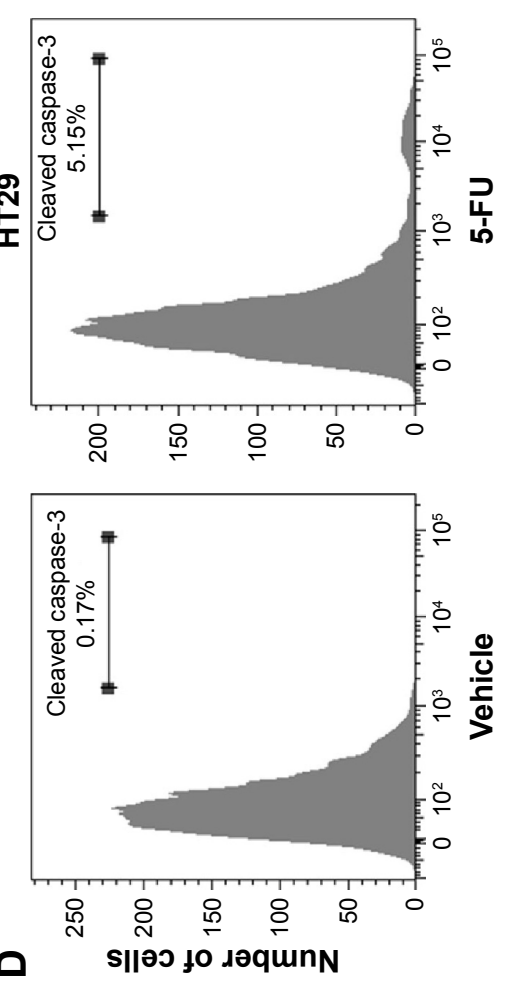

实空

U 몽

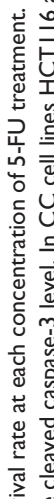

空

岁

亡ั

of

产 弯

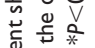

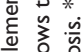

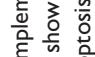

웜 음

突蒈

氖

过

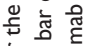

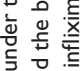

ว 동

乩

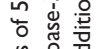

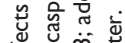

㐘苾

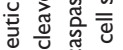

웡 पु

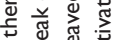

돈

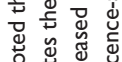

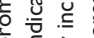

을

赔论

幽完

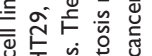

U工 只䒘

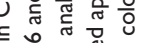

은

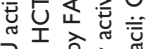

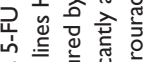

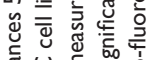

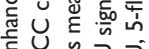

U

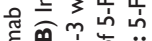

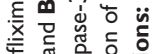


A
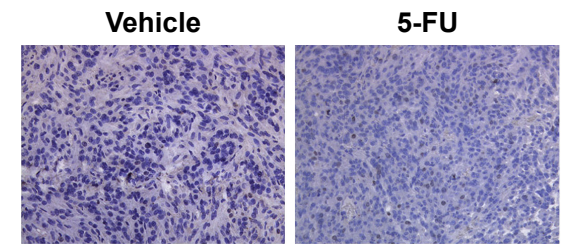

Infliximab + 5-FU

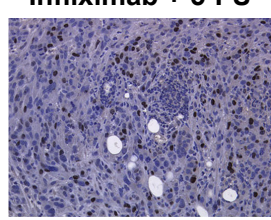

B

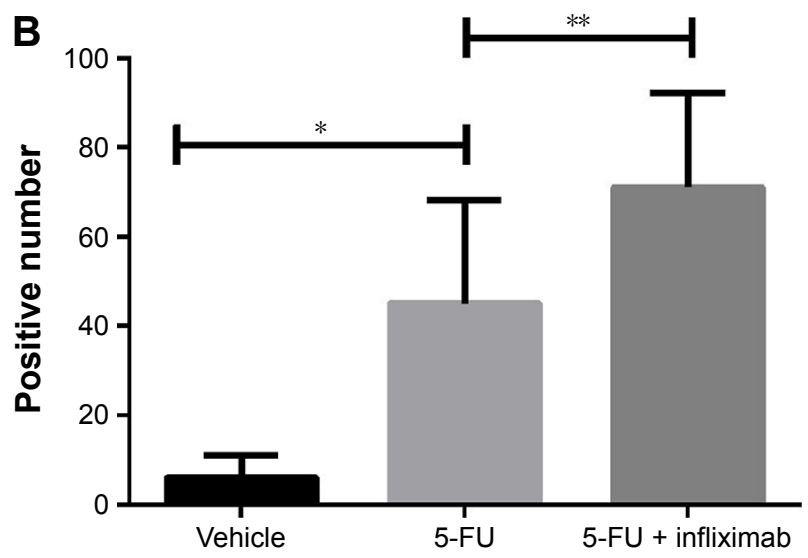

Figure 5 Infliximab and 5-FU combination treatment promotes apoptosis in the CC tissue of the xenograft mouse model.

Notes: Cleaved PARP was evaluated by IHC in the CC tissue of the xenograft mouse model. (A) Representative pictures of IHC staining of cleaved PARP in the CC tissue of the xenograft mouse model. 5-FU treatment induced an increased level of cleaved PARP compared with the control group, while combination of infliximab and 5-FU further increased the level of cleaved PARP in the CC tissue. (B) The bar chart shows the quantitative results of IHC staining of cleaved PARP in the CC tissue of the xenograft mouse model. Compared with the control group, 5-FU and 5-FU + infliximab-treated groups have a significantly increased level of cleaved PARP. $* P<0.05$, $* * P<0.01$.

Abbreviations: 5-FU, 5-fluorouracil; CC, colon cancer; PARP, poly(ADP-ribose) polymerase; IHC, immunohistochemistry.

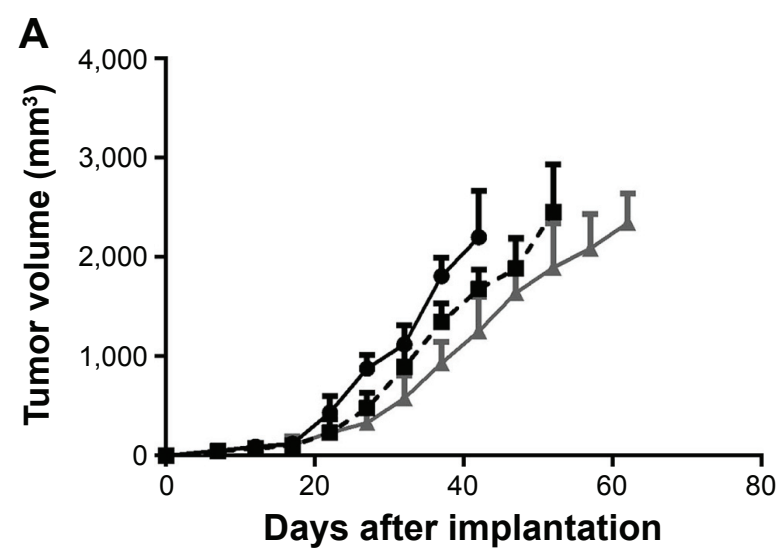

$\rightarrow$ Vehicle - - 5-FU Infliximab + 5-FU

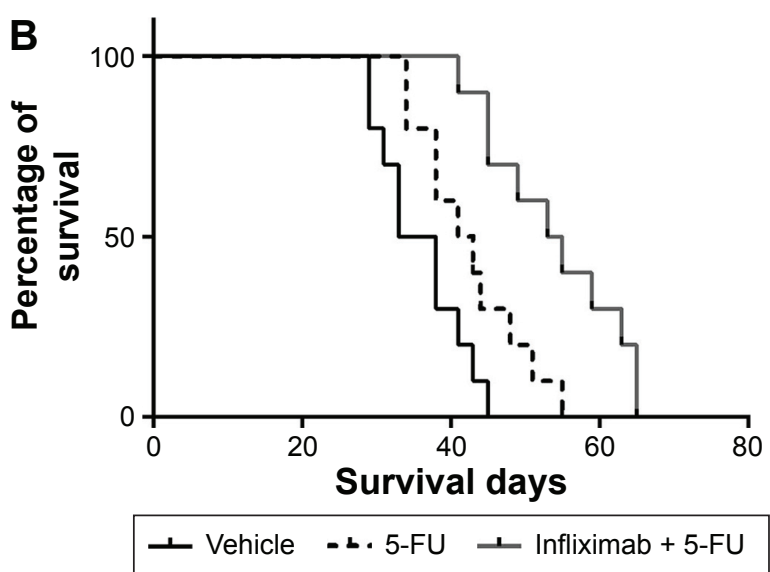

Figure 6 Infliximab enhances the therapeutic effects of 5-FU in the CC xenograft mouse model.

Notes: (A) Tumor growth of the group treated by infliximab + 5-FU is apparently slower than that of the group treated by $5-\mathrm{FU}$ alone. (B) The survival curves indicated that the survival time of infliximab +5 -FU-treated group was extended compared with that of the group treated by 5 -FU alone. Abbreviations: 5-FU, 5-fluorouracil; CC, colon cancer.

\section{Disclosure}

The authors report no conflicts of interest in this work.

\section{References}

1. Siegel R, Desantis C, Jemal A. Colorectal cancer statistics, 2014. CA Cancer J Clin. 2014;64(2):104-117.

2. Torre LA, Bray F, Siegel RL, Ferlay J, Lortet-Tieulent J, Jemal A. Global cancer statistics, 2012. CA Cancer J Clin. 2015;65(2):87-108.

3. Zhao Y, Butler EB, Tan M. Targeting cellular metabolism to improve cancer therapeutics. Cell Death Dis. 2013;4:e532.

4. Carswell EA, Old LJ, Kassel RL, Green S, Fiore N, Williamson B. An endotoxin-induced serum factor that causes necrosis of tumors. Proc Natl Acad Sci U S A. 1975;72(9):3666-3670.

5. Locksley RM, Killeen N, Lenardo MJ. The TNF and TNF receptor superfamilies: integrating mammalian biology. Cell. 2001;104(4):487-501.

6. Hehlgans T, Pfeffer K. The intriguing biology of the tumour necrosis factor/tumour necrosis factor receptor superfamily: players, rules and the games. Immunology. 2005;115(1):1-20.

7. Balkwill F. Tumour necrosis factor and cancer. Nat Rev Cancer. 2009; 9(5):361-371.

8. Moore RJ, Owens DM, Stamp G, et al. Mice deficient in tumor necrosis factor-alpha are resistant to skin carcinogenesis. Nat Med. 1999;5(7): $828-831$.

9. Kulbe H, Thompson R, Wilson JL, et al. The inflammatory cytokine tumor necrosis factor-alpha generates an autocrine tumor-promoting network in epithelial ovarian cancer cells. Cancer Res. 2007;67(2):585-592.

10. Stathopoulos GT, Kollintza A, Moschos C, et al. Tumor necrosis factoralpha promotes malignant pleural effusion. Cancer Res. 2007;67(20): 9825-9834.

11. Harrison ML, Obermueller E, Maisey NR, et al. Tumor necrosis factor $\alpha$ as a new target for renal cell carcinoma: two sequential phase II trials of infliximab at standard and high dose. J Clin Oncol. 2007;25(29): $4542-4549$.

12. Yu M, Zhou X, Niu L, et al. Targeting transmembrane TNF-alpha suppresses breast cancer growth. Cancer Res. 2013;73(13):4061-4074.

13. Egberts JH, Cloosters V, Noack A, et al. Anti-tumor necrosis factor therapy inhibits pancreatic tumor growth and metastasis. Cancer Res. 2008; 68(5):1443-1450.

14. Bosman FT, Carneiro F, Hruban RH, Theise ND. WHO Classification of tumours of the digestive system. (World Health Organization) IARC Press: Lyon, France; 2010. 
15. Edge SB, Byrd DR, Compton CC, Fritz AG, Greene FL, Trotti A, editors. AJCC cancer staging manual. 7th ed. New York, NY: Springer; 2010.

16. Zhao X, He Y, Gao J, et al. Caveolin-1 expression level in cancer associated fibroblasts predicts outcome in gastric cancer. PLoS One. 2013; 8(3): e59102.

17. Zhou X, Zhou S, Li B, et al. Transmembrane TNF-alpha preferentially expressed by leukemia stem cells and blasts is a potent target for antibody therapy. Blood. 2015;126(12):1433-1442.

18. He Y, Zhao X, Subahan NR, Fan L, Gao J, Chen H. The prognostic value of autophagy-related markers beclin-1 and microtubule-associated protein light chain 3B in cancers: a systematic review and meta-analysis. Tumour Biol. 2014;35(8):7317-7326.

19. Pentheroudakis G, Kotoula V, De Roock W, et al. Biomarkers of benefit from cetuximab-based therapy in metastatic colorectal cancer: interaction of EGFR ligand expression with RAS/RAF, PIK3CA genotypes. BMC Cancer. 2013;13:49.

20. Fahmueller YN, Nagel D, Hoffmann RT, et al. Immunogenic cell death biomarkers HMGB1, RAGE, and DNAse indicate response to radioembolization therapy and prognosis in colorectal cancer patients. Int J Cancer. 2013;132(10):2349-2358.
21. Adams GP, Weiner LM. Monoclonal antibody therapy of cancer. Nat Biotechnol. 2005;23(9):1147-1157.

22. Mitoma H, Horiuchi T, Tsukamoto H, et al. Mechanisms for cytotoxic effects of anti-tumor necrosis factor agents on transmembrane tumor necrosis factor alpha-expressing cells: comparison among infliximab, etanercept, and adalimumab. Arthritis Rheum. 2008;58(5):1248-1257.

23. Rolfe M, James NH, Roberts RA. Tumour necrosis factor alpha (TNF alpha) suppresses apoptosis and induces DNA synthesis in rodent hepatocytes: a mediator of the hepatocarcinogenicity of peroxisome proliferators? Carcinogenesis. 1997;18(11):2277-2280.

24. Van Antwerp DJ, Martin SJ, Kafri T, Green DR, Verma IM. Suppression of TNF-alpha-induced apoptosis by NF-kappaB. Science. 1996; 274(5288):787-789.

25. Harris SM, Mistry P, Freathy C, Brown JL, Charlton PA. Antitumour activity of XR5944 in vitro and in vivo in combination with 5-fluorouracil and irinotecan in colon cancer cell lines. Br J Cancer. 2005;92(4): $722-728$.
OncoTargets and Therapy

\section{Publish your work in this journal}

OncoTargets and Therapy is an international, peer-reviewed, open access journal focusing on the pathological basis of all cancers, potential targets for therapy and treatment protocols employed to improve the management of cancer patients. The journal also focuses on the impact of management programs and new therapeutic agents and protocols on

\section{Dovepress}

patient perspectives such as quality of life, adherence and satisfaction. The manuscript management system is completely online and includes a very quick and fair peer-review system, which is all easy to use. Visit http://www.dovepress.com/testimonials.php to read real quotes from published authors. 